\title{
Development of a Muskingum- Cunge routing model for design of furrow irrigation
}

\author{
Hassan Ibrahim Mohamed ${ }^{1}$, Omran Musa Abass ${ }^{1}$, Azza Rahamat Alla Zein Elabdin ${ }^{1}$ and \\ Haitham. Ragab El ramlawi ${ }^{2}$ \\ ${ }^{1}$ Department of Agriculture Engineering, Faculty of Agriculture Studies, Sudan University for \\ Science and Technology. ${ }^{2}$ Centre of Dry land Farming Research and Studies, Faculty of \\ Agricultural and Environmental Sciences, University of Gadaref, Sudan.
}

\begin{abstract}
Surface irrigation projects which accounts for almost all of the irrigated land areas of the world has been studied extensively by many investigators and their performance was found to be lower than expected. Many of these projects are built and operated without adequate technical input, with consequent low uniformity and efficiency of water application. However, irrigators are still faced with significant challenges in making both design and operation of surface irrigation systems more efficient. In this study a mathematical design approach for furrow irrigation was developed as spreadsheet model to simulate all hydraulic phases of water movement as aid to design and to evaluate the performance of furrow irrigation. The irrigation model simulates the hydraulics of furrow irrigation at the field scale. The principle role of the model is the evaluation of alternative field layouts (field length and slope) and management practices (water application rates and cut-off times). Input data requirements for the simulation component include field length, slope, infiltration characteristics (or advance data), target application depth, water application rate, Manning's resistance and furrow geometry. A series of simple relations were presented for estimating the advance, recession, and performance of surface irrigation systems. The approach uses continuity to compute the advance time to field end and half the distance to field end. The irrigation methods differ slightly in how the surface volume is computed. Initially a surface shape factor is used to compute storage volume during advance phase; however, estimation of this storage volume was corrected during storage, depletion and recession phases by utilizing Muskingum-Cunge routing method. The subsurface volume calculations use a modified Kostiakov equation that includes both an initial sink term and a constant final infiltration rate. Recession calculations differ for each method. With sloping methods, adjustments to a straight line recession curve make recession estimates more reasonable. It is shown that the procedure can produce reasonable predictions of design performance over a range of conditions. Model verification was made by its comparison with FAO-surface-model, and zero-inertia model using data from furrow fields of Kenana Sugar Scheme-Sudan.
\end{abstract}

Keywords: Furrow irrigation design model; Muskingum-Cunge routing method; Volume balance; Spreadsheet simulation of irrigation hydraulic phases.

\section{INTRODUCTION}

Surface irrigation is popular, often used as a tool to develop rural areas for it is cheap and requires less know-how. The adoption of improved surface irrigation design and management practices is inhibited both by a low awareness amongst irrigators of the variables affecting irrigation performance and the difficulty of quantifying the benefits associated with alternative practices. Simulation modeling may be used to address both of these issues.

Surface irrigation is the most widely used irrigation method in the world. In Sudan almost all irrigated areas uses surface methods. In the US, over $50 \%$ of irrigated land is watered by surface means. It is the most inexpensive method, in terms of capital outlay, power requirements, and maintenance costs. Traditional surface methods are labor intensive. Poor uniformity of application, and excessive runoff and deep percolation, often carrying agricultural chemicals into the environment, are common. The complexity of the hydraulics of surface systems has, until recently, made rational design very difficult. Accordingly, many surface systems are built and operated without the benefit of any technical design. The proliferation of computers has now made numerical solutions of the hydraulic equations easily attainable, and is putting design of surface irrigation systems and their operation on a par with other 
engineering disciplines -- with reliance on multiple analyses (simulations) with trial values of the design variables in the search for an optimum.

Surface irrigation projects which accounts for almost all of the irrigated land areas of the Sudan. In particular furrow irrigation uses in excess of $70 \%$ of the water used for irrigation in Sudan and is the dominant method of irrigating both horticultural and field crops. The low level of crop productivity in the Sudanese irrigated schemes is attributed by many scholars Farbrother (1973), Adam, H.SI (1992), and Abd el Whab, 2000,) to be mainly due to low levels of management of irrigation water (use of long irrigation intervals, improper field lengths, need for land leveling, inequity and inadequacy of water distributions, excessive silt and accumulation of weeds in canals). To overcome this problem a series of rehabilitation and modernization programs were made in the last decade. Although large sum of money is spent in these projects their outcome is not to the expectation. Less expensive and more effective ways of solving the problem is to adopt better design procedures for furrow irrigation, employ new and advanced technologies for silt removal such as building silt trap ejectors or excluders, alternative on-farm management procedures and water allocation rules and norms for the case of inadequate water supply, capacity building and extension programs to aid the newly established water user associations. To reach a more efficient, accurate and reliable solutions the wisdom of today time is to maximize the benefit from computer modeling facilities. In reality use of the orthodox method of designing new projects (e.g. in El Shahid or El Multaga) into a fixed numbers of $280 \mathrm{~m}$ lengths as used in the past in Gezira Scheme or to arbitrary select various lengths of field runs as the case of Rahad and Kenana Schemes (e.g. in White Nile Sugar Scheme) irrespective of soil type has resulted in excessive runoff water and low water application efficiency.

Many commercial systems have been found to be operating with highly variable efficiencies at significantly lower levels. For example, commercial furrow application efficiencies in the Kenana sugar industry have been found to range from $14-90 \%$ for single irrigations and from $31-62 \%$ for seasonal applications. Similarly, application efficiencies of 30$50 \%$ have been found on cotton farms of Gezira scheme Farbrother (1973) . In the arid and semidesert regions of the Sudan and in particular those of northern parts, irrigation is the only source of water for crop production. Although water scarcity has not been considered a problem, it is expected that the increasing demand for fresh water from municipal and industrial sectors will significantly reduce the share of fresh water supply available for irrigation. Over the past several years, Northern Sudan has experienced a prolonged drought further aggravating competition for the limited water resources. Hence, efficient irrigation is a key element of improved water management in the north region. Thus, efficient irrigation not only conserves water but also impacts positively on the environment by reducing the transfer of pollutants from irrigated lands to the groundwater and surface-water resources. Efficient irrigation can be achieved by better design

With intensification and diversification, the Gezira tenant has developed new field methods of unattended night continuous-flow watering. According to Farbrother, (1971) there is a necessity for research on design of alternative irrigation methods.

Surface irrigation accounts for almost all of the irrigated land area in Sudan (both large schemes e.g. Kenana scheme and small holder farms e.g. Gezira scheme) and over $90 \%$ worldwide. Many schemes are built and operated without adequate technical input, with consequent low uniformity and efficiency of water application. Yet, water supplies for irrigation are limited and likely to decline due to competition from environmental and urban water demands. The decrease in crop yields in these schemes is often attributed to the low performance of furrow irrigation. Consequently, to improve crop productivity it is essential to improve furrow performance. Improvement of furrow performance can be achieved via proper design and better operation. Therefore, science-based criteria for design and management of surface systems are critically needed.

The efficiency of surface irrigation is a function of the field design, infiltration characteristic of the soil, and the irrigation management practice. However, the complexity of the parameter interactions within each of these main influences makes it difficult for irrigators to identify optimal design or management practices under commercial conditions. Abd el Wahab (2000) and Ali et al (2009) identified a range of methods to improve water application efficiencies in the sugar industry (Kenana Scheme) including the use of appropriate furrow lengths, irrigation cutoff times and water application rates. However, one of the main constraints to the improvement of surface irrigation performance has been the inability to provide site specific guidelines without extensive field 
experimentation. While the value of field research should not be underestimated, it is expensive and time consuming with results limited to the range of conditions investigated. Another major obstacle to the adoption of improved management practices at the farm level is the recognition by the irrigator of the benefits associated with implementation. Simulation modeling provides an opportunity to identify more efficient practices and assess the benefits for a fraction of the time and cost of field trials. While irrigation earthworks, water diversion, storage and distribution works are routinely designed in different parts of the World using well defined parameters and models, the surface irrigated field is often poorly designed with little use of either field measured or model data. While a wide range of irrigation design and management tools have been developed to assist irrigation researchers and managers investigate irrigation performance at field scales Strelkoff, , (1991); Walker , (1983). These designs are based on a set of two governing equations: the continuity equation and the momentum equation (i.e. the Saint Venant equations). According to the way in which these basic equations are applied, four types of models are usually distinguished: Volume balance, full Hydrodynamic, Zero-inertia models and Kinematic models.

Full hydrodynamic models are accurate, most complicated, but delicate and require considerable computer time; they can be standards against which simpler models can be tested.

Full hydrodynamic method is often described as the most accurate but as the same time as the most complicated method for design of surface irrigation .To solve the problem zero-inertia were used to simplify the full hydrodynamic method while the kinematic wave method was used to improve the accuracy of the volume balance scheme. Both methods of zero-inertia and kinematic wave are criticized to be less accurate due to in appropriate consideration of temporal and spatial variability of the volume of stored water.

The volume balance model is the simplest to solve and the least complicated to understand. The approach replace the momentum equation by assuming a constant average cross-sectional surface flow area over the length of the field, and thus has, in fact, no real relation "kinematics". The latter is also called "volume balance model" (see e.gWalker , (1987)).
The volume balance model (VBM) is recognized to be the least accurate method to describe the motion of water during its progress down the irrigated field. However, it may give good results compared to those obtained from more sophisticated models such as zero inertia and full hydrodynamic in certain cases, for example with a steep slope and smooth soil surface. Moreover, the VBM is the basis for the early design and evaluation of the surface irrigation systems. The VBM is also the basis for the development and understanding of other surface irrigation models, and it has been used to determine the wetting front of the stream during the advance process.

Volume balance is widely used tool for designing of furrow irrigation due to its simplicity but is described as less accurate compared to other schemes. The classical volume balance based on the concept of normal depth Suffer from the assumption of static surface storage and from use of empirical relation for estimating it. For steep slopes, the surface volume is typically a small fraction of the total inflow volume, such that rough estimates of these parameters give reasonable advance predictions; where typically, Surface storage cross-sectional area is assumed equal to the flow area at normal depth and a correction factor is used and is given a value of 0.7 . For milder slopes or in clay soils the surface volume is often a large portion of the inflow volume, even at the time of cutoff. Also, Surface storage crosssectional area changes continuously during the irrigation event and in some cases never reach normal depth. Hence, advance estimation method for surface irrigation methods need to re-examine the assumptions regarding Surface storage crosssectional area. Hence, more accurate and simple design solutions in the form of spreadsheet-based computer programs have to be developed for flatplanted level furrow-basins and open-ended sloping furrows.

During the advance phase, the general form of VBM stems from the fact that volume delivered to the field should equal those of surface and subsurface

$Q_{0} t=A 0 \sigma_{y} x+\sigma_{z} z_{0} x$

Where: $Q_{0}$ is inflow rate, $t$ is inflow cut off time, $A_{0}$ is the flow area at normal depth $\sigma_{\mathrm{y}}$ is surface storage water shape factor and given a value of $0.7, \sigma_{z}$ is the shape factor of sub-surface infiltrated water and also given a value of $0.7, z_{0}$ is the infiltrated water depth and $\mathrm{x}$ is the advance distance. During advance, the 
volume in surface storage at time $t\left(\mathrm{~V}_{\mathrm{y}}(\mathrm{t})\right)$ may be calculated as:

$V_{y}(t)=y A_{0}(t) x$

Where: Ao (t) is the cross-sectional flow area at the inlet at time $t, \sigma y$ is the surface storage shape factor, $\mathrm{W}$ is the width (all units are in meters and seconds). However, during storage ponding and depletion phase's estimation of $A 0$ and $\sigma_{y}$ is the main problem in predicting surface storage. For steep slopes, the surface volume is typically a small fraction of the total inflow volume, such that rough estimates of these parameters give reasonable predictions; where typically, A0 is assumed equal to the flow area at normal depth and $\sigma_{y}$ is given a value of 0.7 . For milder slopes, the surface volume is often a large portion of the inflow volume, even at the time of cutoff. Both the cross-sectional flow area and $\sigma$ y change continuously during the irrigation event and in some cases never reaches normal depth. However, Clemmens,(2007). claimed that simulation does not satisfy the objective to have simple, spreadsheetbased design procedure. In this study MuskingumCunge routing method is planned to be used to estimate surface storage volume.

The main problem is that the $A 0$ and $\sigma_{y}$ are not known in general. For steep slopes, the surface volume is typically a small fraction of the total inflow volume, such that rough estimates of these parameters give reasonable advance predictions; where typically, $\mathrm{A} 0$ is assumed equal to the flow area at normal depth and $\sigma_{y}$ is given a value of 0.7 . For milder slopes, the surface volume is often a large portion of the inflow volume, even at the time of cutoff. Also, A0 changes continuously during the irrigation event and in some cases never reach normal depth. Similarly, $\sigma_{y}$ can vary. Hence, advance estimation method for surface irrigation methods need to re-examine the assumptions regarding $\sigma_{y}$ and $\mathrm{A} 0$ (t). It has proven useful to compute simulations over a wide range of conditions so that the nature of the problem can be seen and the variation in various shape factors determined. Dimensionless variables have been used to reduce the number of interrelated parameters so that meaningful results can be displayed on a limited number of graphs. Full design solutions have been developed for flat-planted level basins and openended sloping border strips, and are available in the form of computer programs basin Clemmens,(1998). and border (USU , (1991). Both are limited in the type of infiltration function and range of conditions considered. However, this does not satisfy the objective to have simple, spreadsheet-based design methods.

An example of a small "volume-balance" based FORTRAN program for computing uniformity, efficiency and losses in surface irrigation (basin, border or furrow) is mentioned in a standard irrigation textbook James, (1988) and a similar one in Basic for furrow irrigation design in another textbook Cuenca (1989) . The FAO surface irrigation design program surface Walker , (1982) is another example of this approach. A brief description the four named surface irrigation programs follows (for details, see Annex 1). We have not tested a Utah State University surface irrigation simulation model SURMOD USU, (1991), which seems to be able to do roughly the same as the under mentioned SRFR. Finally, the observation by Walker , (1982) is supported; stressing that mathematical treatment of surface irrigation is only one tool in arriving at a good lay-out; other factors like size and shape of individual land holdings, land consolidation programs, farmer preferences, and equipment limitation may have a greater weight. It is good to realize that the mathematical models are only applicable in part of the design process and that uniform water distribution (the core of all discussed models) is only one aspect.

SRFR: This is a model for surface irrigation analysis, rather than for synthesis and design. It was summarized by Strelkoff,, (1991), mentioning limitations as well and there is a manual dating from December USU , (1991),. Again, design values like length of run, inflow rate and cut-off time should be given (together with other relevant parameter values), and the program will yield the ultimate longitudinal distribution of infiltrated water and the volume of runoff. The main differences with its predecessor are (i) that it addresses all three types of surface irrigation, (ii) infiltration, bottom slope and roughness may be varied over the field length, (iii) inflow can be input as constant, as surges or as a hydrograph, (iv) infiltrated volumes between stations are now computed continuously (and not after calculating advance and recession curves at the end of the run) and (v) time and distance step sizes are determined automatically, depending on the specified number of (computational) sections in which the field length will be divided. Running the program requires going through a preparatory program and running time is still about 20 minutes on the Compaq test machine (without a math co-processor). The promised plotting facilities appeared not to be generally applicable and the output remains a long list of figures. 
Agric. Biol. J. N. Am., 2010, 1(5): 1014-1030

Summarizing, the program is still very much researcher-oriented, with a pre-occupation for physical and mathematical theory, typical for the development stage in an academic environment. Appearance and user-friendliness have not been important considerations, apparently, but work on a more comfortable user-interface, especially for input and out, is said to be in progress.

SURFCE: This program belongs to FAO Irrigation and Drainage paper 45 Walker , (1982) but can also be obtained from USU , (1991). It illustrates in Walker , (1982) on surface irrigation design based on the volume balance design method. It can deal with sloping basins, with open-ended or blocked borders, and with three types of furrow irrigation, i.e. traditional systems, systems with a cut-back system and systems with a tail water recirculation facility. Again, this is mainly an analysis program, into which values for design variables like length of run and flow rate are entered, together with slope, application depth, flow geometry, surface roughness and infiltration characteristics. Output then produces a list of possibilities for e.g. border width, unit flow, advance and cut-off time and application efficiencies.

Irrigation system design is a complex process that includes economics, water supplies, and crop selection, etc. Property boundaries, soil texture and its variation, and topography have a significant influence on surface irrigation design. Costs for land grading and construction of canals are a major consideration. The design becomes a compromise between the best dimensions and layouts for each soil texture, how the fields fit within the physical constraints, and economics. Hence, design criteria include furrow width, depth and shape and furrow length, slope of the furrow, inflow rate and application time. The design objectives of furrow irrigation are typically stated in terms of achieving some desired application efficiency, Ea and on supplying the target depth of water at field end

Several software programs are available for performing surface irrigation design calculations. Strelkoff, (1985) made numerous unsteady-flow simulation runs with the zero-inertia model to produce infiltrated depth profiles. Several simulation programs are available for making calculation of advance, recession, and the distribution of water Strelkoff, , (1991), these more accurate solutions avoid some of the assumptions with the methods presented here. However with simulation software, one has to perform simulations by adjusting cutoff time by trial and error to obtain a solution that gives the minimum depth equal to the required depth. This would have to be done for each set of conditions to be examined, that is, each point on the performance contour plot.

Unless the software assists with this process, this is not convenient for routine application.

Clemmens,(1998). suggest the use of the above equations for furrow design, combined with simulation runs with SRFR to adjust the approximations made here such that the solutions to the design equations match the simulation results. Then the adjusted equations are used to develop the performance contours. With this approach, the adjusted solution will be correct at the points where simulations are made and will drift away from the true solution as one moves away from these conditions.

Elliot and Walker , (1990) used a zero-inertia procedure with a specified time step to model the advance phase of an irrigation event. Kinematic wave theory with a specified time step was employed by Walker , (1983) to simulate the entire irrigation event including surged inflow.

Strelkoff, , (1991) used a non-linear zero-inertia procedure with an adjustable time step to model irrigation events including surged inflow. Volume balance analysis with specified space intervals was employed by Wallender, (1986) to simulate the advance phase of an irrigation event. Smedema, (1984) used a cumulative solution of the volume balance equation with specified space intervals to model irrigation events. SIRMOD (Utah State University, 1989) and SRFR Strelkoff, , (1991) are computer models that use the complete hydrodynamic, zero-inertia, or kinematic wave approaches. These two computer models simulate the entire irrigation event including surge flow. The kinematic wave approach executes rapidly and provides reasonable results for slopes greater than or equal to $0.1 \%\{18\}$

A study by Strelkoff, (1985) found that most irrigation designers "guess" the design variables which dominate the performance of surface irrigation. Similarly, few irrigators or extension officers use any form of simulation model or decision support aid to optimize the performance of individual irrigations by selecting flow rates and times to cut-off to maximize performance. This study provides an introduction to one of the more commonly used surface irrigation models and presents case studies which demonstrate its potential for use as a decision support aid to assist both irrigators and consultants in 
the design and management of surface irrigation systems.

In general this study is directed to improve and increase crop productivity and thereby aid in alleviating poverty in rural areas. This because furrow irrigation is widely used in rural areas in both large (e.g. Kenana scheme) and small holder (e.g. Gezira scheme) farms. The decrease in crop yields is often attributed to the low performance of furrow irrigation. Consequently, to improve crop productivity it is essential to improve furrow performance. Improvement of furrow performance can be achieved via proper design and better operation. The specific objectives of the study are:

1. Develop a simple, interactive and easy to run Excel Spread Sheet validated furrowirrigation model (a) for simulating furrowirrigation hydraulics, (b) for assisting in design and management of such systems, and (c) for estimating the field parameters that bear upon system behavior.

2. To improve furrow irrigation design by modifying the classical normal depth volume balance method that Suffer from the assumptions of static surface storage and use of empirical relation for estimating it.

3. To provide quantitative data on the performance of alternative irrigation design and management practices to irrigators and other decision makers

4. Develop guidelines and procedure for design and operation of furrow irrigated fields to improve the efficiency of water application, and storage.

\section{MATERIALS AND METHODS:}

Characteristics of Study Area: Kenana Sugar Estate, situated at $300 \mathrm{Km}$ South of Khartoum and 30 $\mathrm{km}$ South of Rabak town on the east bank of the White Nile in central Sudan (latitude 13o North and longitude 300 East).It is considered as the largest single estates in the world covering an area of 39,916 hectares of cane with potential yield of about 4 million tons of cane Ali et al (2009)

The soil of the Estate is black cotton clay (selfmulching Vertisols) and forms part of the extensive central clay plain of the Sudan. These soils are cracking montmorilinitic with clay a high Base Exchange capacity soils which is hard during dry conditions and sticky under wet conditions. Infiltration behavior of cracking clays is unique in a sense that when dry, the infiltration rate is initially very high but diminishes rapidly when becoming saturated to a point the infiltration rate has become negligible Ali et al (2009) . The degree of cracking or crack volume depends on the moisture status of the soil while the crack geometry and patterns depend on the lateral distribution of the moisture extraction.

The Estate is situated in an arid continental climatic zone. Mean annual rainfall is about $300 \mathrm{~mm}$ and the daily evaporation rate varies from $5 \mathrm{~mm} /$ day in August to $16 \mathrm{~mm} /$ day in March - April.

The project is irrigated from the White Nile water by lift irrigation. The maximum demand of the estate at the peak is $36.75 \mathrm{M} 3 / \mathrm{S}$. The Estate area slopes downwards the river with an average land slope of 0.5 meter per kilometer. From the scheme Western boundary to the river land elevations range from 390 $\mathrm{ms}$ to $429 \mathrm{~ms}$ above seas level. The Estate area is divided in two by a ridge running from North east to South-west from elevation $424 \mathrm{~ms}$ to $410 \mathrm{~ms}$ with two drainage channels. The governing slopes are about 45 degrees to the direction of the drainage channels. The cross contour grades range from 1:25 to 1:1000 with the majority of areas around 1:500.

The main canals which are the main arteries have been designed as hydraulic conveyance, as distinct from the primary canals which have been designed to command the land. Series of primary canals, which constitute the main delivery system, take-off from the main canals forming a net work of about $200 \mathrm{Km}$ and following the contour to serve the agricultural fields. Each primary canal irrigates 2520-3780 ha. The standard unit of the layout is 420 ha and called subsection. The field canal or hydro-flume pipe takes off from the primary canal to irrigate a field of $63-84$ ha average.

Water in the primary canal is diverted into field canals/ hydro-flume running parallel to it. Long furrows of $1.5 \mathrm{Km}$ average length run across the contour of average slope $0.2 \%$ (1:250-1:500). Because of the longer time needed to irrigate long furrows, the night storage system of irrigation was replaced by continuous irrigation which requires full attendance to ensure perfection and water saving.

To attain equity, the land slope, the furrow length, the soil classes and the cane canopy are considered as main factors determining the irrigation cycle through which we are intending to ultimately supply 10,000 cubic meters of water per hectare per crop cycle of 13 months average (irrigation is 12 months). This $10000 \mathrm{M} 3$ is the average of Kenana 
evapotranspiration per 12 months and it is also known to be an international standard for irrigation.

Field Data Collection: Data used was collected from commercial irrigations conducted at Kenana Sugar State site as reported in Abd el Wahab (2000) during the 1997-98 and 1998-99 irrigation seasons (From field No. 11303 for infiltration measurements and from fields No. 1130, 11101, and 41106 for measuring all hydraulic phases of surface irrigation in short, medium and long furrows respectively) and also the data reported by Shatanawi, (1987) during the 2000-2001 and 2001 -2002irrigation seasons(From fields No. 41106,22109,and 41102) and reported by Ali et al (2009). Eleven irrigations events were measured during seasons 1997-98 and 1998-99 and eighteen irrigations during irrigation seasons 2000-2001 and 2001 -2002.

The fields were categorized into long, medium and short according to furrow length and receive water every 12, 10 and 7 days respectively. However, with flatter the field the longer irrigation cycle and length of run is used. In each test soil moisture is determined gravimetrically to one meter depth at $0.2 \mathrm{~m}$ increments. The application efficiency was calculated as the ratio of the average root zone soil water deficit throughout the furrow length and the total volume applied, expressed as a percentage. In all tests, irrigation advance (at $25 \mathrm{~m}$ interval) and all volume balance parameters were measured on three adjacent furrows. However, data were taken from only the medium furrows where at least four advance points were successfully recorded and used in the subsequent analysis. Kostiakov-Lewis infiltration functions in the form:

$\mathrm{I}=\mathrm{kt} \mathrm{t}^{\mathrm{a}}+\mathrm{ft} \mathrm{t}_{\mathrm{o}}$

Where $(\mathrm{I})$ is the cumulative infiltration, $\mathrm{a}$ and $\mathrm{k}$ are fitted parameters, $\left(\mathrm{O}_{\mathrm{f}}\right)$ is the final infiltration rate, and $(t)$ is the infiltration opportunity time, were calculated for each irrigation using the modified two-point method Elliott (1982) . Cumulative infiltration volumes were calculated at 5 minute intervals for each infiltration run and averaged to provide data for determination of average infiltration function.

Climatic Data: The reference evapotranspiration (ETO) for Kenana estate was computed using the FAO -Penman -Monteith approach and the CROPWAT software for each month of the growing season upon entry of the required meteorological data.
Climatic data for 30 years (from 1977 to 2007) collected from the sugarcane research meteorological station were used for the prediction of the reference evapotranspiration $\left(E T_{0}\right)$. using the Penman - Monteith method, results show that the mean annual value of the reference evapotranspiration is $6.1 \mathrm{~mm} \mathrm{day}^{-1}$ and the value for March and April, (the highest months ) are very close begin ( $7.7 \mathrm{~mm}$ day $^{-1}$ and $7.4 \mathrm{~mm}$ day $^{-1}$ respectively). During August (rainy season) the reference evapotranspiration reaches its minimum value of 4.5 $\mathrm{mm}$ day $^{-1}$.

Soil Data: At each location along the tested furrow soil water content and bulk density for depth intervals of $20 \mathrm{~cm}$ through one meter were measured using gravimetric method (Willard et al., 1958). Soil samples for gravimetric moisture determination were collected at furrow top. Middle and bottom for evaluation the soil moisture defect prior to the irrigation. Then the gravimetric moisture content $(\mathrm{w} / \mathrm{w})$ was converted to volumetric values $(\mathrm{v} / \mathrm{v})$ by multiplying by the dry bulk density. . Field capacity and permanent wilting point were approximated using the pressure plate membrane (Ritchard, 1965). Field capacity was found to reach a value of $38.9 \%$ and wilting point a mounts to $21.6 \%$ on weight basis. These values are in agreement with those given by Abdelwahab (2000) and Ali et al (2009) .

Result of water content before and after irrigation indicate that under the existing irrigation system irrigation was carried - out in the evaluated fields when the depletion level at $0.5 \mathrm{~m}$ soil depth reaches 0.37 whereas the lowest depletion level for irrigation sugarcane is about 0.68 . According to the soil water content the mean applied depth at $0.5 \mathrm{~m}$ soil depth was calculated as the difference between the water content before and after irrigation multiplied by depletion level and the effective root zone depth. It was found to be ranging from 40 to $45 \mathrm{~mm}$ whereas the required irrigation depth is around $68 \mathrm{~mm}$.

Crop Data: The seasonal amount of water requirement for sugar cane crop was determined as a function of the local climatic crop and soil data. To account for the effect of the crop characteristics on crop water requirements sugar cane crop coefficients (kc) were determined following the procedure described by Abdelwahab (2000).

Measurement of Hydraulic Parameters (discharge, infiltration, furrow geometry, advance, and recession:

-Discharge measurement: an evaluation was made of the existing furrow irrigation system adopted under 
Kenana conditions. Nine fields having different furrow lengths and slopes were evaluated. In this study, only three fields are presented namely, (Field: 11101, 11303 and 41106). In each field a group of four consecutive furrows were tested. Using as near constant pressure head as circumstances permitted in the earth field canal.

Irrigation water was siphoned out onto the cane row through a three inches internal diameter siphon-tube. The inflow rate through siphon tube, which is a function of the pressure head causing flow, was computed using the following formula:-

$$
\begin{aligned}
& q=0.65^{*} 10-3^{*} a\left(2^{*} g^{*} h\right) 0.5 \text {--- } \\
& \text { Where: } \\
& q=\quad \text { Discharge from siphon tube }(1 \mathrm{~s}-1) . \\
& a=\quad \text { Area of the cross-section }\left(\mathrm{cm}^{2}\right) . \\
& \mathrm{g}=\quad \text { Acceleration due to gravity }\left(\mathrm{cm} . \mathrm{s}^{-2}\right) . \\
& \mathrm{h}=\quad \text { Pressure head causing flow }(\mathrm{cm})
\end{aligned}
$$

Pressure is the difference in elevation between water surface in the field canal and the centre of the outlet under free-flow conditions or the water surface above the outlet when the outlet is submerged. The field evaluation measurement started from the third irrigation event, so that the rate of change of infiltration rates and the effect of differences in the intake opportunity times would be minimized.

Infiltration measurement: furrow intake rates were measured with inflow-outflow technique following the procedure proposed by Merriam, (1978) . This inflow-outflow technique represents real conditions because when water moves down the furrow and infiltrates into the soil surface it rearranges the surface particles. it was based on the concept that the difference between inflow and outflow in a furrow at any time is the infiltration rate. The equipment used for the determination of infiltration rate by the inflow-outflow method include: Surveying tape, Stopwatch, Three plastic siphon tubes of three inches internal diameter, two Parshall measuring flumes of $50 \mathrm{~mm}$ throat width, with staff gauge. The flumes were placed along a furrow with a 36 meter distance between them. Then the inflow-outflow rates were determined following the procedure described Walker , (1987). The flow at the upstream end of the furrow is the inflow and that at the downstream end is the outflow. Irrigation water was delivered to the furrow from the field canal using siphon tubes.
To minimize the lateral movement of irrigation water, only the middle furrow was computed, whereas, the outer two furrows served as buffers. With this method discharge from both devices was recorded with time. The infiltration rate was then calculated by dividing volume differences in discharge from both flumes by the length of the tested furrow. The modified Kostiakov-lewis formula, which accounts for a soil's basic infiltration rate is used for the determination of the cumulative intake:

$\log (z-c t)=(a) \log (t)+\log (k)$

Where:

$z z=$ Infiltrated volume
infiltration opportunity time, $t$.

$$
\begin{gathered}
c=\text { Basic intake rate in units of volume per } \\
\text { unit length per unit time. }
\end{gathered}
$$

$\mathrm{k}$ and $\mathrm{a}=$ empirical fitting parameters.

As stated by Wallender, (1986) and Strelkoff, , (1990) the basic intake rate of Vertisols is reached after 3 to 4 hours of watering. The basic intake rate was found using the following equation;

$c=\left(q_{\text {in }}-q_{\text {out }}\right) / \mathrm{l}$

Where: $c=$ the basic intake rate $(m 3 m-1 m i n-1), q_{\text {in }}$ and $\mathrm{q}_{\mathrm{out}}=$ the inflow and outflow rates, respectively, in $\mathrm{m} 3 \mathrm{~min}^{-1}$, and I = Furrow length $(\mathrm{m})$.

Using the infiltration data and from the plotted graph of $\log (t)$ against $\log (z-c t)$, the coefficient, $a$, in the infiltration (equation 5) is determined as the slope of the line. Whereas the value of infiltration parameter, $k$, as the value at the $y$-intercept at time, $t=1$. After three hours of watering value of the steady- state final infiltration, c, in the modified Kostiakov equation is computed independently, as the difference between inflows and outflow rates. An average value of $0.00005 \mathrm{~m}^{2} \mathrm{~min}^{-1}$ per meter of furrow length was obtained. Based on the collection field data the infiltration parameter was determined as the slope of the regression line. The value of 0.446 for $a$, is within the range of value normally experienced in heavy clays. The value of the constant, $k$, is determined as the $y$-intercept at time, $t=1$ on a log-log scale. The value of the parameter $\mathrm{k}$ was found to be around $0.0019 \mathrm{~m}^{3} \mathrm{~m}^{-1} \mathrm{~min}^{-\mathrm{a}}$.

Furrow geometry: During furrow evaluation, the cross- sectional geometry was measured at furrow top, middle and bottom. The measurements were taken just before irrigation and three days after irrigation following the method suggested by Elliott 
(1982) and Walker , (1990). A profile-meter for determining the cross- sections of furrows was used, which consisted of a series of 19 movable iron rods, $30 \mathrm{~cm}$ long and mounted at $5 \mathrm{~cm}$ intervals. At each station, the rods were lowered until they touched the soil surface. The individual scales on the rods of the profile-meter provided data to plot furrow depth, $y$, as function of the lateral distance. Then the depth of the flow, $y$, and the cross- sectional flow area, A, were related mathematically with the power function as follows:

$y=b A^{h}$

Where, $b$ and $h$ are constant. The wetted perimeter was also determined as a power function of the cross-sectional area, $\mathrm{A}$, as follows:

$A^{2} R^{4 / 3}=d A^{f}$

In which $d$ and $f$ are empirical constants.

Cross- sectional profile data are collected at furrow top, middle and bottom using furrow- profile-meter. These data are then integrated and a geometric relationship is used to relate the cross- sectional area and wetted perimeter with depth. The empirical parameters $b, h, d$ and $f$ were determined throughout the irrigation season using a tow - point fit of the data, and their values were as:

$$
b=0.39 \quad h=0.6 \quad d=0.21 \quad f=3.3
$$

Measurement of advance, and recession: The most important field data are the advance rate, which can vary throughout the irrigation season. The empirical procedure followed for determination of the advance trajectory was based upon the following steps:

i) Using field stakes and surveying tape, the tested furrows were divided into a number of stations having equal distances between them.

ii) As the irrigation water advanced down the furrow, arrival times were recorded at the end of each reach. Then, the advance trajectory was represented by a power function following a tow point procedure as described by Elliott (1982)

$\mathrm{X}=\mathrm{P}\left(\mathrm{t}_{\mathrm{a}}\right)^{\mathrm{rx}}$

Where, $X$ is the advance distance in $m$, achieved in $t$ a minutes of inflow. $P$ and $r$ are fitting parameters. When the flow area was equal to $10 \%$ of the maximum cross- sectional area, recession times were observed and recorded at each station.

Measurement of runoff: When the advance stream reaches the end of the tested furrow, the inflow discharge was ceased by removing the siphon tube. Then, the flow discharge per furrow was measured with a $50 \mathrm{~mm}$ throat - width Parshall measuring flume and the discharge rate in liter per second $(\mathrm{L} / \mathrm{s})$ was computed using the following formula as suggested by $\{21$ )

$\mathrm{Q}=0.1207$ ha1.55

Where: $\mathrm{Q}=$ Flow rate of $50 \mathrm{~mm}$ Parshall measuring flume $(\mathrm{L} / \mathrm{s}), \mathrm{H}_{\mathrm{a}}=$ Head of the water at converging section $(\mathrm{m})$. Also, rectangular thin- plate weir is used for measuring the loss of irrigation water via runoff from the field end. Then, the tail water discharge was computed following Francis equation:

$Q=0.0184 L^{3 / 2}$

Where: $\mathrm{L}=$ the weir crest width $(\mathrm{cm}), \mathrm{H}=$ Total energy head on the weir $(\mathrm{cm})$. The first readings were recorded at shorter time intervals (every 2 minutes), when the tail water discharge reached a steady state, readings of the water head were recorded every 15 minutes.

Data Analysis and Evaluation of Model Performance: For purpose of data entry in the model the required inputs were tabulated and analyzed using descriptive statistics (mean, standard deviation, percentage, standard error --- etc.). Clemmens,(2007). modified volume balance is coded in Excel format and used for model verification. Likewise, the results of analysis of Kenana field data using zero-inertia model reported by Abdel Wahabl (2005) was used for model validation.

\section{MODEL DEVELOPMENT}

Objective and Scope of the Design Model: The surface irrigation system should replenish the root zone reservoir efficiently and uniformly so crop stress is avoided. Resources like energy, water, nutrients, and labor should be conserved. The irrigation system might also be used to cool the atmosphere around sensitive crops or to heat the atmosphere to prevent their damage by frost. An irrigation system must always be capable of leaching salts accumulating in the root zone. It may also be used to soften the soil for better cultivation or even to fertilize the field and apply pesticides.

The design procedures outlined in the following sections are based on a target application depth, $Z_{\text {req, }}$ which equals the soil moisture extracted by the crop. Design is a trial and error procedure. A selection of lengths, slopes, field inflow rates and cutoff times can 
be made that will maximize application efficiency for a particular configuration. Iterating through various configurations provide the designer with information necessary to final a global optimum. Considerations such as erosion and water supply limitations will act as constraints on the design procedures. Many fields will require a subdivision to utilize the total flow available within a period of availability. This remains a judgment that the designer is left to make after weighing all other factors that are relevant to the successful operation of the system. Maximum application efficiencies, the implicit goal of design, will occur when the least-watered areas of the field receive a depth equivalent to $Z_{\text {req. Minimizing }}$ differences in intake opportunity time will minimize deep percolation. Surface runoff will be controlled or reused. The decision variables in surface irrigation are normally the field dimensions (furrow length and spacing), the flow rate, and the cutoff time.

Model Assumptions Limitations and Requirements: The model utilizes units of SI system. It assumes that the user can predict or measure infiltration characteristic using modified Kostiakov empirical equation. Furrow geometry is assumed as U-shape. Soils are assumed to be uniform. Sloping irrigation systems will be oriented down the existing slope.

To run the developed model the system requirements includes the same minimum system requirements of all Microsoft Office editions in the 2003 release that runs on the Microsoft Windows Me, Windows 98, or Windows NT operating systems.

Model Inputs: Consider collection of the following Design data:

- Field properties: field area (ha), Length $(m)$.The length of run for irrigation will be less than the field dimension, requiring that the field length be broken up into different irrigation units of equal size. Slope in direction of length $(\mathrm{m} / \mathrm{m})$, Width $(\mathrm{m})$, Slope in direction of width $(\mathrm{m} / \mathrm{m})$, Available flow rate, $Q(1 / \mathrm{s})$.

-Soil characteristics: Infiltration coefficients: $k$ is the constant coefficient $\mathrm{m} 3 / \mathrm{mina} / \mathrm{m}$ of length, in the modified Kostiakov function. (a), is the constant exponent. (c), is the basic intake rate, $\mathrm{m} 3 / \mathrm{min} / \mathrm{m}$ of length ( $Z=\mathrm{kra}+\mathrm{cr}$ modified Kostiakov function).

Where: $Z$ is the accumulated intake in volume per unit length

-Furrow geometry characteristics: For furrows, the following geometry is assumed: Furrow length $(L), m$; Furrow width $\left(\mathrm{W}_{\mathrm{f}}\right)$, $\mathrm{m}$; Furrow flow $\left(\mathrm{Q}_{\mathrm{f}}\right)$, L/s; Furrow slope $\left(S_{f}\right), m / m$; Manning roughness coefficient, $n$ .The Manning $n$ values have been observed as low as 0.03 on smooth furrows and as high as 0.4 on closely planted wheat. Also, furrow irrigated crops with vegetation which hangs into the water can cause much greater resistance than the Manning $\mathrm{n}$ of 0.04 .

Resistance to flow is usually described by the Manning equation, which relates the flow rate, $Q$, to the flow area, $A$, the hydraulic radius, $R$ (area over wetted perimeter), the friction slope, $\mathrm{Sf}$, and the Manning $\mathrm{n}$ :

$Q=A R^{2 / 3} S_{f}^{1 / 2} /(n / C u)$

Expressed in terms of flow rate per unit width, $q$, for border strips and basins, this becomes:

$\mathrm{q}=\mathrm{y}^{5 / 3} \mathrm{~S}_{\mathrm{f}}^{1 / 2} /(\mathrm{n} / \mathrm{Cu})$

Where $y$ is the flow depth and $q=Q / W$, where $W$ is the basin or border width. Surface storage shape factor $\left(\sigma_{y}\right)$; Depth required $\left(Z_{\text {req }}\right), \mathrm{mm}$. For furrows and border strips, the surface shape factor will be assumed as $\sigma_{y}=0.75$. For level systems $\sigma_{y}=0.80$.

Considering furrow shape factors $(b, h, d, f)$ the flow cross-sectional area may be defined such as:

$A 0=((Q 0 n) * 2 /(3600 d s f))(1 / f)$

, and $y=b A^{h}$

Where: $A_{0}$ is furrow inlet flow area $\left(\mathrm{m}^{2}\right)$ and $y$ is flow depth $(\mathrm{m})$. As given byClemmens,(2007). input design parameters can be summarized as in the table below:

Required minimum input data for surface irrigation process

\begin{tabular}{|c|c|}
\hline $\begin{array}{l}\text { Parameter and } \\
\text { notes }\end{array}$ & $\begin{array}{l}\text { Mathematical } \\
\text { functions }\end{array}$ \\
\hline Infiltration constants: & $A, k, O_{f}$ \\
\hline $\begin{array}{l}\text { Manning } \\
\text { roughness from } \\
\text { field data }\end{array}$ & $\mathrm{N}$ \\
\hline $\begin{array}{l}\text { Field } \\
\text { geometry(Length } \\
\text {, slope, unit } \\
\text { width) }\end{array}$ & $\mathrm{L}, \mathrm{W}_{\mathrm{f}}$, So, and $\mathrm{w}$ \\
\hline $\begin{array}{l}\text { Parameters of } \\
\text { cross-sectional }\end{array}$ & Tmax, Tmid,Ymax \\
\hline $\begin{array}{l}\text { Soil erosive } \\
\text { velocity }\end{array}$ & $\mathrm{V} \max$ \\
\hline $\begin{array}{l}\text { In flow rate and } \\
\text { time }\end{array}$ & $\mathrm{Q}_{\mathrm{T}}, \mathrm{t}_{\mathrm{T}}$ \\
\hline $\begin{array}{l}\text { Application requirement } \\
\text { depth }\end{array}$ & Zreq. \\
\hline
\end{tabular}


Design Processes: The design process starts by assigning a length and flow rate to each furrow. This calculation procedure is followed for a series of values for the length and flow rate. These values are compared in making design choices. The conceptual flow chart is depicted in figure (1).

Inputs required for design process includes: infiltration functions, flow geometry, field slope and length, to determine the rates of advance and recession. Once advance and recession are computed, the field performance levels for various combinations of inflow and cutoff times are determined. Thus, the two important design computations in surface irrigation design are: (1) computation of the advance time; and (2) computation of the time when the inflow is shut off, or cutoff time, $\mathrm{t}_{\mathrm{co}}$.

The steps needed in the design Processes are outlined below.

\section{Calculate required depth of application $\left(\mathrm{d}_{\mathrm{req}}\right)$ :}

Surface irrigation systems have a narrow range of target or required depth of application $\left(\mathrm{d}_{\text {req }}\right)$ for which they are reasonably efficient and uniform. Design approaches are often based on assuming that one end of the field or the other will receive the least infiltrated depth. Then, the inflow and application time are adjusted such that the required depth is infiltrated at that location.

2. Calculate the opportunity time required to infiltrate the desired application depth:

The time to infiltrate the required depth, $T_{\text {req }}$, becomes an important design parameter. Following Clemmens,(2007). and figure (2) the infiltration opportunity time at any location, $x$, along the lengthof-run, $T_{o p p}(x)$, is defined as the time between advance, $t_{A(x),}$, and recession, $\operatorname{tR}(x)$ or

$t_{\text {opp }}(x)=t_{R(x)}-t_{A}(x)$

At the head end of the field $(x=0)$, the opportunity time is equal to the recession time, or

$\mathrm{t}_{\mathrm{opp}}(0)=\mathrm{t} \mathrm{R}(0)=\mathrm{t}_{\mathrm{co}}+\mathrm{t}_{\text {lag }}$

-- $(17)$

Where $t_{c o}$ is the time of cutoff or application time and $t_{\text {lag }}$ is the recession lag time, or the time required for the water depth at the upstream end to drop to zero after cutoff.

With the minimum depth at the downstream end of the field, furthest from the water source $(x=L)$, advance and recession curves must be computed.

$$
t R(L)=t A(L)+t \text { req }
$$

The time of cutoff that will produce the target depth at the downstream end is

$$
t_{c o}=t A(L)+t_{r e q}-\left[t_{R}(L)-t_{R}(0)+t_{\text {lag }}\right]-----(19 a)
$$

Where: the term in brackets is the time between cutoff and recession at the downstream end.Then the application time is found from:

$\left.\mathrm{t}_{\mathrm{co}}=\mathrm{t}_{\mathrm{A}}(\mathrm{L})+\mathrm{t}_{\text {req }}-\left(\mathrm{V}_{\mathrm{y}}\left(\mathrm{t}_{\mathrm{co}}\right) / \mathrm{Q}_{\mathrm{in}}\right)-18 \mathrm{~b}\right)$

3. Calculate normal depth.

4. Computation of Advance Time: Compute advance times to half field length and to end of field length. Computation of the cutoff time.

Computation of advance time: The time required for water to cover the field, the advance time, $t L$, necessitates evaluation or at least approximation of the advance trajectory. Input data include the inflow discharge, $Q_{0}$; the field length, L; the infiltration coefficients $\mathrm{k}$, $a$, and of; the field slope, So; and the flow cross-section area $A_{o}$ based on the cross-section geometry parameters $\rho 1$ and $\rho 2$. The Volume balance advance equation may be stated as:

$$
t=s x^{\lambda} \ldots \ldots(19 b)
$$

It contains two unknowns, $s$ and $\lambda$. In order to solve them, a two-point advance trajectory is defined in the following procedure:

1. The power advance exponent $\lambda$ typically has a value of 10-1.1. The first step is to make an initial estimate of its value and label this value $\lambda 1$, usually setting $\lambda 1=2.5$ to 1.67 are good initial estimates. Then, a revised estimate of $\lambda$ is computed and compared below.

2. Calculate the subsurface shape factor, $\sigma z$, from the following equation:

$\sigma_{z}=(\lambda+a(\lambda-1)+1) /((1+a)(1+\lambda)) \quad \ldots \ldots .(20)$

3. Calculate the time of advance, th, using the following Newton-Raphson procedure:

a. Assume an initial estimate of tL as T1

$$
\mathrm{T} 1=5 \mathrm{~A} \circ \mathrm{L} / \mathrm{Q}
$$

o.

b. Compute a revised estimate of $t L(T 2)$ as:

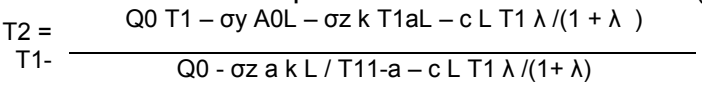

c. Compare the initial (T1) and revised (T2) estimates of $t L$. If they are within about 0.001 minutes or less, the analysis proceeds to step 4 . If they are not equal, let $\mathrm{T} 1=\mathrm{T} 2$ and repeat steps $\mathrm{b}$ through $\mathrm{c}$.

4. Compute the time of advance to the field midpoint, $t$ 0.5L, using the same procedure as outlined in step 3 . The half-length, $0.5 \mathrm{~L}$ is substituted for $L$ and $t 0.5 \mathrm{~L}$ for $\mathrm{tL}$ in Eq. (3) and (4).

5. Compute a revised estimate of $\lambda$ as follows:

$$
\lambda 2=\frac{\log \left(t_{\llcorner} / t_{0.5 L}\right)}{\log (2)}
$$


6. Compare the initial estimate, $\lambda 1$, with the revised estimate, $\lambda 2$. The differences between the two should be less than 0.0001 . If they are equal, the procedure for finding $t \mathrm{~L}$ is concluded. If not, let $\lambda 1$ $=\lambda 2$ and repeat steps 2-6.

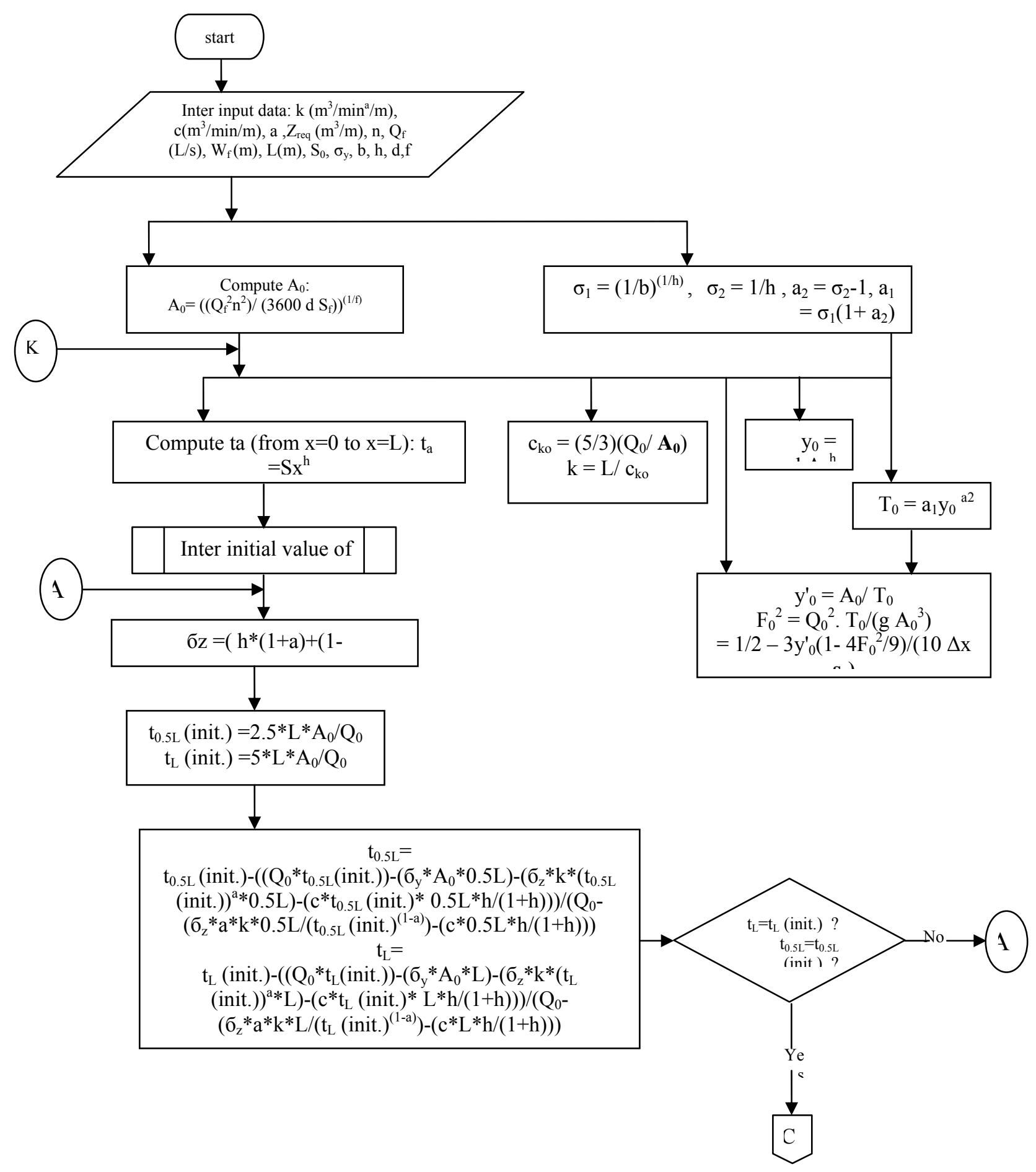


Agric. Biol. J. N. Am., 2010, 1(5): 1014-1030

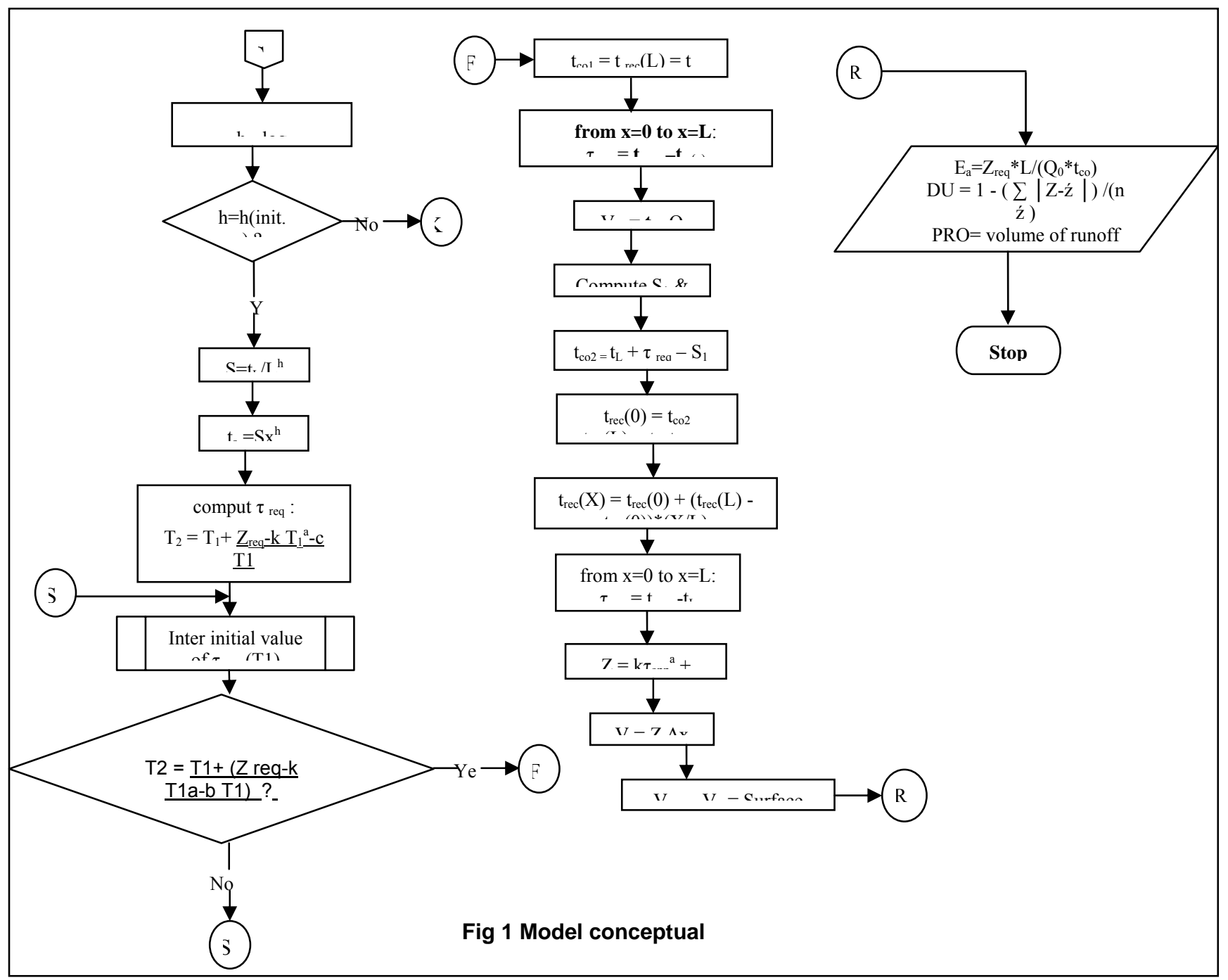

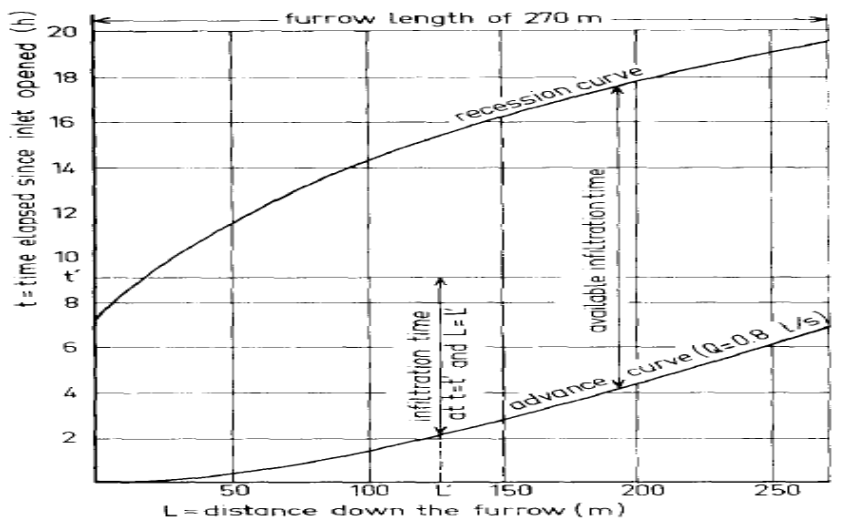

5. Fig 2: Advance and recession curves and definitions for design satisfying the target depth at the downstream end (Source: A.J. Clemens (2007) Simple approach to surface irrigation design: Theory.

When the correct value of $\lambda$ is achieved we can easily calculate the value of $S$ using equation (4-1), with either
$(\mathrm{x}=\mathrm{L}$ and $\mathrm{t}=\mathrm{tL})$ or $(\mathrm{x}=\mathrm{L} / 2$ and $\mathrm{t}=\mathrm{t} \cdot 5 \mathrm{~L})$. Let the irrigation distance be subdivided into $\mathrm{N}$ segments of equal length $\Delta \mathrm{X}$, which requires $\mathrm{N}$ variable time steps $\Delta t$

The advance time at any location, $x$, along the length-ofrun, $\mathrm{ta}(\mathrm{x})$, is defined from equation (19)

As given above, there are two advance times that must be estimated, and they influence each other through the advance exponent, automatic convergence routines for a single cell are cumbersome. An alternative solution procedure was developed that provides easier convergence, although it requires circular references. Rather than iterating on the advance times, the spreadsheet can be set up to iterate on the advance exponent. Iteration on the advance time is done through a circular reference, based on the user input advance exponent.

The advance time results provide a new estimate for advance exponent. The solution converges rapidly. With this approach, automatic calculation of cell formulas is turned off so that these circular references will not cause 
difficulties. The user needs to remember to repeatedly force calculation (F9 key in excel) until the solutions converge. Some spreadsheet software programs do not allow circular references, so this method is not used in the spreadsheets provided.

Computation of the time required to achieve the required depth: The basic mathematical model of infiltration is the modified Kostiakov function:

$$
\mathrm{Z}=\mathrm{kT}^{\mathrm{a}}+\mathrm{CT}
$$

Where $Z$ is the accumulated intake in volume per unit length, $\mathrm{m} 3 / \mathrm{m}$ (per furrow or per unit width are implied), $\mathrm{T}$ is the intake opportunity time in minutes, (a) is the constant exponent, $\mathrm{k}$ is the constant coefficient $\mathrm{m} 3 / \mathrm{mina} / \mathrm{m}$ of length, and $c$ is the basic intake rate, $\mathrm{m}^{3} / \mathrm{min} / \mathrm{m}$ of length. In order to express intake as a depth of application, $\mathbf{Z}$ must be divided by the unit width. For furrows, the unit width is the furrow spacing, wf, Values of $\mathrm{k}, \mathrm{a}, \mathrm{b}$ and wf along with the volume per unit length required to refill the root zone, Zreq, are design input data. The design procedure requires that the intake opportunity time associated with Zreq be known. This time, represented by $\mathrm{T}_{\text {req, }}$, requires a nonlinear solution to Eq. (24). The convenient method for those with programmable calculators or microcomputers is the Newton-Raphson procedure which is three simple steps as follows:

1. Make an initial estimate of $\mathrm{T}$ req and label it T1;

2. Compute a revised estimate of $\mathrm{T}_{\mathrm{req}}, \mathrm{T}_{2}$ :

$\mathrm{T} 2=\mathrm{T} 1+(\mathrm{Z}$ req-k T1a-b T1 $) /(\mathrm{ak} /(\mathrm{T} 11-\mathrm{a})+\mathrm{b})$

3. Compare the values of the initial and revised estimates of $\mathrm{T}_{\text {req }}$ (T1 and T2) by taking their absolute difference. If they are equal to each other or within an acceptable tolerance of about 0.5 minutes, the value of $\mathrm{T}_{\text {req }}$ is determined as the result. If they are not sufficiently equal in value, replace T1 by T2 and repeat steps 2 and 3

\section{Computation of the cutoff time:}

1-The case of horizontal recession:

$$
\mathrm{T} \text { co }=\mathrm{t} \operatorname{rec}(\mathrm{L})=\mathrm{t} \operatorname{rec}(\mathrm{X})=\mathrm{tL}+\text { treq ------26) }
$$

Where $t \operatorname{rec}(L)=$ recession time at the lower end of the field. $T$ rec $(X)=$ recession time at any distance $X$. Infiltration volume is predicted using the modified Kostiakov function:

$$
\mathrm{V}=\mathrm{Z} \Delta \mathrm{x}=\Delta \mathrm{x}(\mathrm{kTa}+\mathrm{cr})
$$

Where $V$ : cumulative infiltration volume $(\mathrm{m} 3), \Delta \mathrm{x}$ : routing reach length $(\mathrm{m}), \mathrm{Z}=$ is the accumulated intake in volume per unit length, $\mathrm{m}^{3} / \mathrm{m}$ (per furrow or per unit width). $Z$ is predicted at the upstream and downstream ends and averaged to determine the infiltration volume within the reach:

$\mathrm{T}=\mathrm{t} \operatorname{rec}(\mathrm{L})-\mathrm{t} \mathrm{a}(\mathrm{x})$

Where ta $(\mathrm{x})$ : advance time at distance $\mathrm{x}$ :

$\mathrm{V}$ in $=\mathrm{Q} 0 \mathrm{t}$ co

Where $\mathrm{V}$ in: the inflow volume $\left(\mathrm{m}^{3}\right)$.

The application time can be adjusted to take storage into account with Equation (25). The advance curve is used to construct advance at eight equal increments of length. Recession times are interpolated between the values at the ends of the field. Infiltration opportunity times are computed as the difference between recession and advance times
(Equation (28)), from which infiltrated depths are computed (Equation (24)). The infiltrated depths are averaged over each distance interval, converted to volume by multiplying average depth by the length and width, and then summed to give total volume infiltrated. The runoff volume is computed as the difference between the inflow volume and the infiltrated volume.

General Muskingum Method: The equation defining storage routing, based on the principle of conservation of mass, can be written in approximate form for a routing interval t.

Assuming the subscripts " 1 " and "2" denote the beginning and end of the routing interval, the equation is written as follows:

$$
\left(\mathrm{O}_{1}+\mathrm{O}_{2}\right) / 2=\left(\mathrm{I}_{1}+\mathrm{I}_{2}\right) / 2-\left(\mathrm{S}_{2}-\mathrm{S}_{1}\right) / \Delta \mathrm{t}
$$

The known values in this equation are the inflow hydrograph and the storage and discharge at the beginning of the routing interval. The unknown values are the storage and discharge at the end of the routing interval. With two

unknowns $\left(\mathrm{O}_{2}\right.$ and $\left.\mathrm{S}_{2}\right)$ remaining, another relationship is required to obtain a solution. The storage-outflow relationship is normally used as the second equation. How that relationship is derived is what distinguishes various storage routing methods.

The continuity equation can be manipulated to get both of the unknown variables on the left-hand side of the equation:

$\left(\mathrm{S}_{2} / \Delta \mathrm{t}\right)+\left(\mathrm{O}_{2} / 2\right)=\left(\mathrm{S}_{1} / \Delta \mathrm{t}\right)+\left(\mathrm{O}_{1} / 2\right)-\mathrm{O}_{1}+\left(\mathrm{I}_{1}+\mathrm{I}_{2}\right) / 2$

31)

Since $(\mathrm{I})$ is known for all time steps, and $\mathrm{O}_{1}$ and $\mathrm{S}_{1}$ are known for the first time step, the right-hand side of the equation can be calculated. The left-hand side of the equation can be solved by trial and error. This is accomplished by assuming a value for either $\mathrm{S}_{2}$ or $\mathrm{O}_{2}$, obtaining the corresponding value from the storage-outflow relationship, and then iterating until the Equation above is satisfied. Rather than resort to this iterative procedure, a value of $t$ is selected and points on the storage-outflow curve are repotted as the "storage-indication" curve. This graph allows for a direct determination of the outflow (O2) once a value of storage indication $(\mathrm{S} 2 / \mathrm{t}+\mathrm{O} 2 / 2)$ has been calculated.

The Muskingum method assumes that the surface storage in the reach can be written as a linear function of inflow and out flow: Where:

$$
S=K[\theta I+(1-\theta) O]
$$

$S$ is the surface storage $(\mathrm{m} 3)$

$I$ and $O$ are the inflow and the outflow respectively ( $\mathrm{m} 3 / \mathrm{min})$ $\mathrm{K}$ and $\theta$ are Muskingum parameters

$\mathrm{K}=\mathrm{L} / \mathrm{cko}$

$\theta=1 / 2-3 \mathrm{y}_{0}^{\prime}(1-4 \mathrm{~F} 02 / 9) /\left(10 \Delta x \mathrm{~S}_{0}\right)$

Where:

cko $=5 Q_{0} / 3 A_{0}$

$\mathrm{y}^{\prime}{ }_{0}=\mathrm{A}_{0} / \mathrm{T}_{0}$

And $F_{02}=Q_{02} T 0 / g A_{0} 3$ (37)

Where: $Q_{0}, A_{0}$ and $T_{0}$ are the reference flow rate and the corresponding area and top width respectively. 


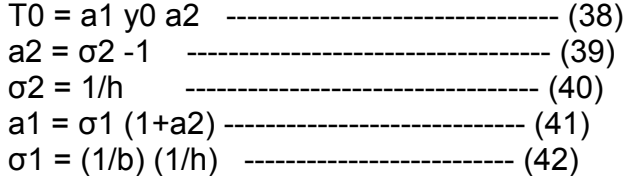

For the case of horizontal recession use the subscript 1 with $\mathrm{V}$ in, $\mathrm{V}, \mathrm{S}, \mathrm{O}, \mathrm{I}$ and $\mathrm{t}$ co :

$$
\mathrm{Vin} 1-\mathrm{V} 1=\mathrm{S} 1+\mathrm{O} 1 \mathrm{tco} 1 \ldots .(43)
$$

Solving equation (32) and equation (43) results the value of S1\&O1

The case of adjusted recession

$$
\mathrm{t}_{\mathrm{co} 2}=\mathrm{tL}+\mathrm{T} \text { req }-\mathrm{S} 1 / \mathrm{Q} 0
$$

$$
t_{r e c}(0)=\text { tco2 }
$$

$\mathrm{t}_{\text {rec }}(\mathrm{L})=\mathrm{tL}+\mathrm{T}$ req

$\operatorname{trec}_{\text {rec }}(X)=\operatorname{trec}(0)+(\operatorname{trec}(L)-\operatorname{trec}(0))^{*}(X / L)$

After the recession time at any distance is determined the we can repeat equation (27), (26), (29), (32) and (43) and solve them for the case of adjusted recession with the new cutoff time and new opportunity times.

\section{Model Outputs:}

Application Efficiency $($ Ea) $=($ Zreq L $) /($ Q0 tco $)$------ (48) Christiansen's Uniformity $(\mathrm{CU})=(1-(\Sigma \mid Z$-ź $\mid) /(\mathrm{n}$ ź) $)$ (49)

Where: $z$ is the average value of $Z, n$ is the segment number.

Percentage Runoff $(P R O)=$ [volume of runoff $/[$ volume of water applied to the field]

Deep Percolation Ratio: (DPR) = 1 - Ea - PRO ------ (51)

Storage Efficiency (Es) = (Ź/ Zreq---------------- (52)

These results fully describe the design results for the selected length and flow rate. Solution to the design problem requires that these results are obtained for a range of lengths, application depths and flow rates. To aid in the process of recording the performance results for each combination of variables, an additional table is provided at the bottom of the spreadsheet. The row with data provides the results from one design run. This can be copied to another worksheet as values, from which a series of results can then be analyzed or graphed.

\section{RESULTS AND DISCUSSION}

Model Verification: Model validation or verification is made here in two steps. First: to test the developed model representation of reality and to discover facts about the model behavior in comparison to other models. This is be made by comparing the field measured time of advance to end of furrow run (ta) with that estimated by the developed model and zero-inertia model Shatanawi, (1987) Second: to compare the developed model with recently developed and improved volume balance model of Clemmens,(2007). in order to explain the developed model structure and operation. This is made by statistical test of a set of evaluating parameters of including: Advance time to field end $\left(t_{\mathrm{L}}\right) \mathrm{min}$, Time of cut off $\left(\mathrm{t}_{\mathrm{co}}\right) \mathrm{min}$, Application Efficiency (Ea \%), Storage Efficiency (Es) \%, Christiansen Uniformity (CU \%) and Recession time to end min (tr).

Model Comparison with Zero inertia Model and Field Data: Figure 3, 4, and 5 shows the behavior of advance phase as measured in the field in comparison with that predicted by the developed Muskingum Model and Zero-inertia Model for furrow lengths of 412,930 and 1580 $\mathrm{m}$ respectively. For short furrows $(200-600 \mathrm{~m})$ the behavior of zero-inertia is typical while Muskingum deviate a little. Statistical test using chi-squire indicates that there is no significant difference between the two models and the field data (Calculated chi-squire values are 0.000500848 and 3.15605E-05 for Muskingum and Zero-inertia model respectively. While the tabulated value at $(p=0.001)$ and 0.995 level of significance is 0.207 ).

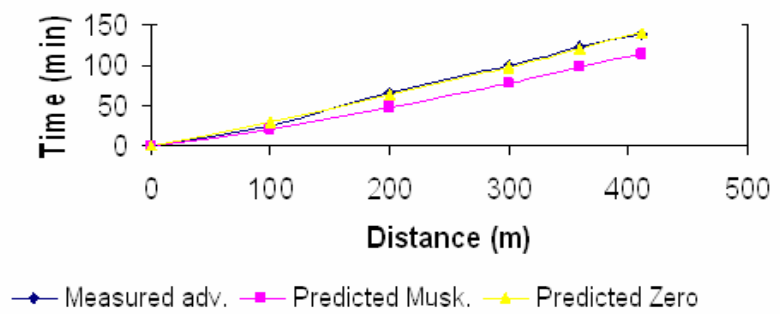

Fig 3: Measured and Predicted Advance time for 412 m furrow Length.

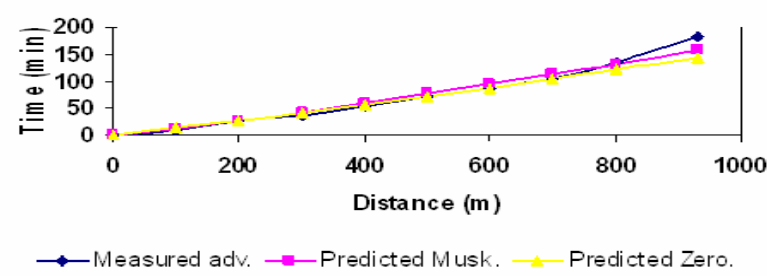

Fig 4: Measured and Predicted Advance time for $930 \mathrm{~m}$ furrow Length

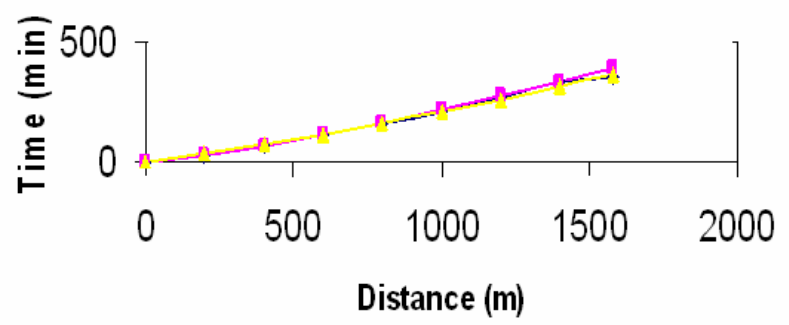

$\rightarrow$ Measured adv. $\rightarrow-$ Predicted Musk. $\rightarrow$ Predicted Zero.

Fig 5: Measured and predicted advance time for $1580 \mathrm{~m}$ furrow Length.

In medium furrows $(800-1200 \mathrm{~m})$ the behavior of the two tested models is almost following the field data till the length of $800 \mathrm{~m}$. Thereafter they deviate a little but statistical test using chi-squire shows no significant difference between the two models and the field data (Figure 5). (Calculated chi-squire values are 0.456 and 0.146 for Muskingum and Zero-inertia model respectively. 
While the tabulated value at $(P=0.001)$ and 0.995 level of significance is 1.735).

Figure 5 shows that for long furrows $(1200-1600 \mathrm{~m})$ prediction of advance rate by the two models is typical to that measured in the field. Calculated chi-squire values by Muskingum Model (0.728) and by Zero-inertia Model (0.395) do not differ significantly from the tabulated values $(0.989)$ at $(P=0.001)$ and 0.995 level of significance.

\section{Comparison Hydraulic Performance of the} Modified Volume Balance Model with Clemmens (2007) Model:

As detailed in the literature review(chapter two) Clemmens,(2007). modified the classical normal depth volume balance model by considering effects of surface storage in estimating time of cut off. To determine surface storage volume Clemmens,(2007). employed numerical approximations by assuming a shape factor of 0.77 for correcting surface storage area at furrow head. As an improvement steps this study use Muskingum-Cunge as a more accurate method to predict surface storage volume. Figure 5.4 shows the performance of the developed model for predicting advance and recession rates for $400 \mathrm{~m}$ length furrow. However, input data used is that given by Clemmens,(2007). .

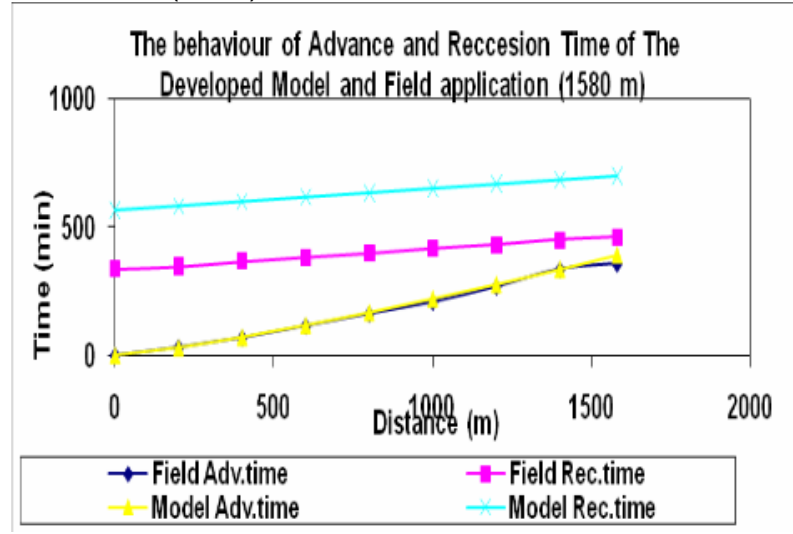

Fig 6: Estimation of advance and recession phases for $400 \mathrm{~m}$ furrow using Muskingum and Clemmens Models.

It is evident from the chart of figure 5.4 there small difference in time of cut off as estimated by the two methods and Clemmens Model give earlier start of cut off time without giving due allowance to surface storage water. Table 6 compares the performance of Muskingum and Clemmens Models with respect to: Advance time to field end min $\left(t_{1}\right)$, Time of cut off $\left(t_{c o}\right)$ min, Application Efficiency (Ea \%), Storage Efficiency (Es \%), Christiansen Uniformity (CU \%), and Recession time (to) end min ( $t_{r}$ ).

Determination of standard error of estimation shows that the difference in estimating the evaluation parameters in these short furrows is small.

\section{CONCLUSIONS}

The main target of this study is to improve classical normal depth volume balance model for design and operation of furrow irrigation by considering the impacts of volume of surface storage in data mining the cutoff time to achieve optimum irrigation efficiencies. This objective is made by employing the Muskingum - Cunge routing technique to modify the design procedure suggested by Clements (2007). From the results the following conclusion can be drawn:

-The hydraulic behavior of the developed model does not differ significantly from actual field data or ZeroInertia model or Clements model.

- Comparison of the actual practices of irrigation in Kenana with results of model simulation for short, medium and long furrows reveals that:

- As given in figure 5.5, 5.6 and 5.7 recession time measured in the field is lower than that predicted by the developed model for furrows of all length. This will lead to very low opportunity time and consequently less water application depth $(0.022 \mathrm{~m}, 0.025$, and0.036 for 412,930 .and 1580 furrow lengths respectively) compared to design depth (of $0.045 \mathrm{~m}$ for short furrows and $0.040 \mathrm{~m}$ for the other furrow lengths given in table 5.2-,5.3, and 5.4). The developed design procedure is considered a suitable tool to be utilized for other irrigation projects. For future research to improve the developed model it is strongly recommended to test the model sensitivity by evaluating the impacts of changing model inputs on achieved out puts. REFERENCES

Abdel Wahab, D.M. 2005, Evaluation, Prediction and optimization of long furrow irrigation under Kenana conditions. PhD Dissertation, water Management and irrigation Institute, University of Gezira, Wad Medani, Sudan.

Adam, H.S. (1992). Sugarcane water requirement calculation using CROPWATT. Proceeding of the Irrigation seminar Organized by Central Statistics Department. Kenana, Sudan, October, 1992.

Ali M. S. M., Saeed A. B., and Mustafa M. A. (2009) Appraisal of spatial and temporal variation of the soil moisture profile in the long furrow irrigation system in Kenana Sugarcane Plantation. Journal of Science and Technology - Sudan University of Science and Technology Vol.10 No.1 Jan pp 71-81.

Clemmens, A.J. (1998). Level basin design based on cutoff criteria.- Irrigation and Drainage Systems 12(2): 85113.

Clemmens, A.J. (2007). Simple approach to surface irrigation design: Spreadsheet applications Sakia.org e-publish, http://www.sakia. org/ejlw, e-Journal of Land and Water, 2007, Vol. 1: 20-43.

Cuenca, R.H. (1989) . Irrigation system design: an engineering approach. Prentice-Hall, Englewood Cliffs, USA, 236-242.

Elliott, R.L. and Walker, W.R. (1982). Field evaluation of furrow infiltration advance functions. Trans. ASAE 25, $396-400$

Farbrother, H.G. (1971). Crop water requirements of sugarcane and net irrigation requirements in the North 
West Sennar area. Agronomy and crop physiology section. Gezira Research Station

Farbrother, H.G. (1973). Water requirement of crops in the Gezira. Annual report of the Gezira Research Station, 1972/73, pp. 139-172.

James, L.G. (1988). Principles of Farmlrrigation System Design. John Wiley \& Sons, New York, 543 pp.

Merriam, J.L. and Keller, J. (1978). Farm Irrigation System Evaluation: A Guide for Management, Agricultural and Irrigation Engineering Department, Utah State University, Logan UT, 271 pp. Furrows - Basins Borders. U.S. Water Conservation Laboratory, 4331 East Broadway, Phoenix AZ. WCL Report \#17. 75 pp. December.

Mohammed, A.A (1984) A Zero-inertia model for design of furrow irrigation. A PhD. Thesis Colorado State University Fort Collins,USA.

Rayej, M. and Wallender, W.W. (1987). Furrow model with specified space intervals. J. Irrig. And Drainage Eng. ASCE 113(4): 536-548.

Shatanawi, M.R. (1980). Analysis and Design of Irrigation in Sloping Borders. Ph.D Dissertation, Smedema, L.K. (1984). Furrow irrigation design for Vertisoils. Agric. Water Manage 9: 211-218.

Strelkoff, T. (1985). BRFRFLW: a mathematical model of border irrigation. USDA, Agric. Research Service, Phoenix, USA.
Strelkoff, T. (1991). SRFR - a model of surface irrigation version 20. In: Ritter, W.F., 1991: Irrigation and drainage, Proc. 1991 National Conf. Irr. and Drainage Div. ASCE, Honolulu, Hawaii, July 22-26, 1991: 676682.

Strelkoff, T., 1990. SRFR - a computer program for simulating flow in surface irrigation. WCL report 17. US Water Cons. Lab., Phoenix, USA.

USU (1992). Surface Irrigation Simulation Model User's Guide. Utah State University Foundation, L Computer Software Summary. Department of Biological and Irrigation Engineering, Utah State Univ., Logan, USA.

Walker, W.R. (1982). Guidelines for designing and evaluating surface irrigation systems. Food and Agriculture Organization of the United Nations Irrigation and Drainage Paper 45.

Walker, W.R. and Busman, J.D. (1990). Real-time estimation of furrow infiltration. Journal of Irrigation and Drainage Engr, ASCE, 116(3): 299-318.

Walker, W.R. and Humpherys, A.S. (1983). Kinematicwave furrow irrigation model. Journal of Irrigation and Drainage Engineering ASCE 109(4): 377-392.

Walker, W.R. and Skogerboe, G.V. (1987). Surface irrigation: theory and practice. Prentice-Hall, Englewood Cliffs, USA.

Wallender, W.W. (1986). Furrow model with spatially varying infiltration. Trans. ASAE 29(4): 1012-1016. 